\title{
Installed water resource modelling systems for catchment management agencies
}

\author{
MC Dent \\ Computing Centre for Water Research, c/o University of Natal, P/Bag X01, Scottsville 3209, South Africa
}

\begin{abstract}
Following international trends there are a growing number of modelling systems being installed for integrated water resource management, in Southern Africa. Such systems are likely to be installed for operational use in ongoing learning, research, strategic planning and consensus-building amongst stakeholders in the catchment management agencies (CMAs). These installed systems are poised to change fundamentally, the way modelling is approached in Southern Africa. They are a logical and irreversible response to the enormous forces which have led to the revision of the South African Water Law and the water resource management paradigms which it embodies.

This paper examines the business forces behind this paradigm shift and it explores the evidence of the changes already taking place in terms of the modelling technology and the organisational and individual responses. Such installed modelling systems are essential for the social process of water allocation as well as for dealing with externalities.

Given the paucity of observed data in Southern Africa, it follows that in many decision-making situations the model is not required to produce accurate answers, for we would have no way of checking their accuracy. Rather it is a tool to help organise a negotiation or learning process in which its primary function is to provide a framework for thinking by enabling the participants to make their implicit assumptions explicit in a systematic manner. This, in turn, provides a means for stakeholders to visit the possible consequences of their intended actions. The creativity and opportunities for compromise which this process releases is where the real benefit of modelling lies.

Recurrent themes in this paper will be the business, technical and human resource issues pertaining to the use of installed modelling systems in the social process of water allocation.
\end{abstract}

\section{Introduction}

The hydrological world is already interrelated. We do not have to create its interrelatedness. Our challenge is to enable our organisations and scientific disciplines to achieve a measure of interrelatedness so as to understand better and, hence, manage within the hydrological world. This interrelatedness is explicitly recognised in the New Water Act and has resulted in institutional and management changes.

One such change is that, following international trends, there are a growing number of modelling systems being installed for integrated water resource management on a catchment basis in Southern Africa. Such systems are likely to be installed for operational use in ongoing learning, research, strategic planning and consensus-building amongst role players in the CMAs. These installed systems are poised to change the way modelling is approached in Southern Africa. They are a logical and irreversible response to the enormous forces which have led to the revision of the South African Water Act and the water resource management paradigms.

Recurrent themes in this paper will be the business , technical and human resource issues pertaining to the use of installed modelling systems in the social process of allocation.

\section{Forces driving the creation of installed water resource modelling systems}

The water resource modelling industry, like any other, is shaped primarily by the external environmental forces operating on the

용(033) 260-5177; fax (033) 260-6288; e-mail: dent@aqua.ccwr.ac.za Received 23 February 2000; accepted in revised form 5 April 2001. business of the industry. In Southern Africa these forces have changed substantially over the past 10 years. Political change has been profound. This has led to large changes in the social forces and paradigms and to the rising economic value of water as aspirations are released. The political, economic and social forces of globalisation have also been substantial and computer communications technology is in the forefront of the external technological forces shaping the industry. The direction of change induced by the information technology revolution is not predestined as may be presumed. Quadir et al. (1999) writing for the Global Water Partnership initiative which is developing a World Water Vision for 2025 state that;

"the impacts of information technology on the water sector are not inherent in the technology but largely depend on the way society chooses to use the technology. The new technology does offer unprecedented possibilities to change knowledge relationships which impact on power relationships and consequently on organisations and society at large." (Quadir et al., 1999)

One of the significant effects of the rising value of water has been a redistribution of intellectual power in the water science field.

\section{Re-alignment of intellect}

Twenty-five years ago most of the water resource science and management intellect resided in state departments. Such an intellectual power setting was adequate to cope with the "get more water" and the "use water more efficiently" eras. Today a significant intellect resides with stakeholder groupings who are in contention for water resources. This shift in the balance of intellectual power holds important strategic implications for the development and use of integrated water resource modelling systems which are used in 
the social process of water allocation. The state has a duty to ensure equity under these circumstances. The new bargaining paradigms discussed in this paper will assist the state in this task. In addition, the opposing contentions amongst the stakeholders over the quality and quantity of the water resources will ensure the checks and balances required to restrain any potential abuse of intellectual power. The powerful intellects will essentially be arranged against one another in a multi-sided rather than a two-sided debate.

The new South African Water Law makes provision for the state to share the responsibility for managing water resources with CMAs. The exact nature of representation on CMAs as well as their structure, functions and responsibilities have not yet been finalised. The latter are not strategically significant for water resource modelling. What is highly significant for the modelling industry is the manner in which these CMAs will be informed on the science and systems of the water which they will be managing in cooperation with the state. The forces on and responses by these intellectual groupings are going to be vital in determining the strategic direction of water resource modelling in Southern Africa. To enhance the understanding of the sections which follow, it is important to pause for a moment to consider these forces and likely responses by the top level scientific consultant groups which will inevitably emerge to advise various stakeholder groupings. It is here that the computer, business and social science worlds will integrate to form the new paradigms and opportunities.

It is inevitable that industries such as forestry, sugar, irrigation, mining and conservation will channel their efforts through topclass cadres of water science consultants who will specialise in the interests of their members. This will immediately create ties which cut across catchment boundaries as many of these industries span large geographic areas. They will create enormous de facto forces for inter-operability standards within and between industries on water modelling issues. The adoption of such standards will create free time to enable the added complexity, of the issues to be dealt with adequately. Driven by the twin forces of time and complexity a key search will be for areas of duplication and unnecessary nonconformity to inter-operability standards.

The arrangements outlined above will greatly elevate the level of intellectual input into water allocation decisions as only the best in each disciplinary area will suffice. The state, in particular, will not wish to have a completely different information generation system in each of the 19 CMAs as this will exacerbate the already extended skills capacity situation. Stakeholders who pay for the modelling and information systems in the CMAs will have a major influence in determining which models are applied and which inter-operability standards emerge. The computer industry has shown that it is extremely capable of using de facto inter-operability standards to drive systemic innovation. The current relationship between DWAF and consultants regarding models will inevitably be altered by this dynamic. Much of the remainder of this paper will focus on the practical implications of these forces on water resource modelling.

\section{Information, options, decisions and conflict resolution}

It is commonly stated that models are useful for generating information about the water resource systems so that options can be considered and decisions taken to manage the resource and resolve conflict. This description of the issues was adequate for the eras of "getting more water supplies" and of "using water more efficiently" Turton (1999). However, we are now in the era of "equitable allocation". Allocation is a social process and, therefore, fundamental paradigm changes take place in the process and the modelling technology is affected directly. The words information, options, decisions and resolution now require qualification as listed below:

- credible information; trusted information; shared understanding of information

- sensible options; innovative options

- shared understanding of consequences of decisions; acceptable decisions; wise decisions

- equitable resolution;- peaceful resolution; lasting resolution; timely resolution

A key questions is; how are credibility, trust, shared understanding, sensibility, acceptability, wisdom, equity and peace achieved? The processes which yield these types of information, options, decisions and resolutions are clearly not ones based on creating information through uni-disciplinary, uni-organisational models and unilaterally disseminating the information with little prospect of receiving and responding to feedback. They will be:

- processes which offer regular, affordable and meaningful communication amongst all stakeholder representatives and their top level scientific consultants;

- processes which are flexible and iterative;

- processes which increasingly reveal more information on the system dynamics;

- processes which are open and transparent;

- processes which enable implicit assumptions and mental models to be made explicit;

- processes which foster generative leadership (Senge, 1990) and adaptive management;

- processes which will incorporate and reflect the inputs of all stakeholders;

- processes which will involve a form of integrated systems simulation modelling which can function in a data poor environment;

- processes which overcome the barriers to communication between stakeholders which arise from geographic, disciplinary and organisational separation.

Implicit in all these processes is a requirement to develop skills and technology to enable the phenomena of inference, connectivity, credibility, trust, assumptions, perceptions, relationships and coordination to flourish. All these phenomena and especially that of co-ordination between groups require extensive practice to manage effectively. Well-designed information systems, especially those which contain information-generation software (models), require practice and feedback in their development and wise application. All the systems must also link to the systems which DWAF has and is developing.

\section{Simplifying the problems with terms of reference}

One of the most important implications of the new Water Act will be that interdependent problems can no longer be simplified to a uni-disciplinary dimension by "bounding" them in the terms of reference for the job. This is evident from a study of the following extracts from the Policy White Paper (DWAF, 1997).

- The objective in relation to our neighbours is the same as it is within our borders , to ensure that we adjust to the pressures and demands of the future through co-operation, not conflict, 
in harmony with the needs of our common development goals and the protection of the environment

- The Constitution moves us away from the old approach that pitted environmental goals against economic and development ones and requires, instead, that they be integrated ( $p .7)$

- The Constitution provides that all spheres of Government and all organs of State must co-operate with each other in mutual trust and goodfaith by co-ordinating their actions and legislation with each other. Co-operative governance and integration are not only policy matters - they are constitutionally mandated (p. 7)

- Water resources cannot be managed in isolation from other natural resources (p. 9)

- The complexity of all these interactions calls for a complex and integrated approach to water management (p.9)

Previously we were primarily concerned about what happened within compartments into which we had divided the problem for our own convenience. We truncated concern at the artificial boundary set by the terms of reference. Now the shortcomings of this approach are recognised and cognisance is taken of what happens at the interface as the results of each process are passed on to the interdependent components of the overall system. Understanding and managing the dynamics of the interdependencies is at the core of integration.

The subject of integrated water resource management (IWRM) is so broad and complex that modellers are unanimous in their opinion that no single model can be used for IWRM, to the exclusion of all others. One hears, repeatedly, the notion that it should be "horses for courses". This is fair comment. However, the needs of IWRM demand that we take our thinking a step further since each CMA will have a plethora of "courses" which are required to be managed, simultaneously and in an integrated fashion. Part of our present predicament is due to the fact that in the past we have attempted to manage only that aspect of the water resource i.e. one "course", which happened to be the issue at the time. Hence, in the past it was easier to allow the "horses" to work separately on the chosen "course". As shown above, the new Water Act demands that this limited and often damaging paradigm must change. The new Water Act places a demand for a team of integrated "horses" to work on the full range of "courses" simultaneously and in an integrated fashion. In other words, that feedback, inter-dependencies and influences between component models are made explicit.

A key modelling search in integrated water resource management must be for a system which facilitates inter-operability between the time-dependent data and information which each "horse" produces. In other words, an overall "operating system" or nested sequence of systems which enables reasonably flexible linking of the components of individual models, if sensible in terms of the processes being modelled.

\section{Optimising innovation and control}

This will require a delicate balance between control and the intellectual and technological space within which to innovate. The challenge requires individual but also group and systemic innovation. Chesbrough and Teece (1996) offer an explanation of systemic innovation as one whose benefits can only be realized in conjunction with related complementary innovations. This is a most important principle to accept for designers of water resource simulation software who are intending to make a contribution to integrated water resource management. Chesbrough and Teece (1996) believe that systemic innovations pose a unique set of management challenges regarding information exchange, sharing and coordinated adjustment throughout the entire product system and often the organisation/s involved. They maintain that co-ordinating a system innovation is particularly difficult when industry standards do not exist and must be pioneered. The issue of standards is discussed briefly below. According to Chesbrough and Teece (1996), experience has shown that once a new inter-operability standard has been established, then virtual organizations can manage further innovation quite well. Inter-operability standards should not be confused with quality standards. These findings relating to systemic innovation are supported strongly by Upton and McAfee (1996) who reported on a number of innovative virtual factories which link across networks to have physical components manufactured at remote sites.

According to Zachary (1994) the developers of Microsoft Windows NT addressed the issue of co-ordinated systemic innovation in a tough but ingenious manner through peer-imposed standards. These and numerous other examples demonstrate that integrated modelling efforts require a conscious commitment to inter-operability standards in certain areas. This commitment should have the effect of inducing a cultural change that when we are exposed to the modelling efforts of others within or allied to our discipline we should think how we can complement, rather than compete with, these efforts. To give practical effect to the desire to complement, we need to seek those parts of the software which are common or standard, in the two systems which we wish to integrate. The generic elements of the service utilities for input, internal management of time series and output visualisation of data are generally such components. World-class utilities with such functionality are now available in the public domain and are supported by giant organisations such as the US Environmental Protection Agency (EPA) and the Water Resources Division of the US Geological Survey (USGS) who are developing strong relationships with the Environmental Systems Research Institute (ESRI), the developers of ARC/INFO and ARC/VIEW.

The operation and maintenance of large interlinked and/or integrated modelling systems will require a blend of freedom to create and innovate and, at the same time, control to enable interoperability. This is the core dilemma facing many industries. We can learn a great deal from the computer hardware and software industry in terms of coping with such seemingly contradictory forces. In an excellent treatment of the subject, Cusumano (1997) explains how Microsoft enables large teams to behave like small teams. The key is inter-operability control at the interface.

The paradox of control and freedom is aptly illustrated by Winston Churchill who said,

"For the first 25 years of my life I wanted freedom. For the next 25 years of my life I wanted order. For the next 25 of my life I realized that order is freedom." (Covey, 1994)

Order and discipline of adhering to inter-operability standards frees up time to devote to complexity, innovation, creativity and dialogue.

\section{Myths and misconceptions about modelling and information systems}

Myths and misconceptions about information systems for water resource management abound. Belief in myths drives behaviour 
and, thus, although these myths are seldom discussed explicitly, the behaviour of individuals and organisations indicates that these myths are strongly implicit in their framework of thinking.

\section{Myth: All the information is available somewhere}

It is a myth that all the information necessary for integrated water resource management is available and that it is simply a case of finding the information, putting it together in a GIS and/or a relational database and disseminating it on the Web. The plethora of efforts to compile lists of meta data and information, with no clear goal thereafter is an indication that this myth is a strong implicit driver of behaviour. The fact is that most of the information required for integrated water resource management is not available and has to be generated through models of various forms. As discussed above, the credibility of this generated information is a key factor in integrated water resource management since it impacts on the shared understanding, trust, acceptability and wisdom.

\section{Myth: Set-up costs of multi-functional installed systems are high}

The set-up costs for multi-functional modelling systems can never be judged in isolation. They should always be reviewed in relation to the benefits and the alternatives. Software production and use has an economic logic of its own. Mass re-production of software means that cost of purchase of software is low in relation to the full functionality in the package. Usage costs are only incurred when the extra functionality is used. In other words, if one does not require a particular group of functions, then save time by:

- $\quad$ not switching them on;

- not reading that section of the manual;

- not learning how to use them;

and not incurring the cost of gathering data for them.

We all engage this time-management and economic logic every day with operating systems, word processing, spreadsheet and other packages. We only incur the cost as and when we wish to derive the benefits, as long as that portion of the application is not affected by the parts which are not invoked. The key point is that with "complex" multi-functional models, we are given this opportunity, whereas with simplistic models we are not.

\section{Myth: Models are objective}

Models (information generation systems) are not objective. In essence, they are a sequence of assumptions, each of which is subjective. Information generation systems (models) are often referred to as being objective because once the subjective assumption has been made, it is applied consistently at all times (unless specifically changed). In this sense, the information generation system (model) is consistent in its subjectivity. Models are not as "fickle" as humans who can and do change their minds.

The subjective nature of models which generate information has an effect on their use in negotiations. As Reitsma et al. (1996) report, the sharing of models and information among interest groups assumes the acceptance by all parties of those models. Reitsma et al. (1996) state that at first this may seem straightforward and non-problematic since models are intended to represent the objective properties of the natural resource. However, since information generation-systems are the product of human thought and are, in essence, a sequence of assumptions, they typically have a subjective cultural background. In addition, they are often developed within groups or organizations that also partake in the negotiation process, either as parties or as external domain experts. Reitsma et al. (1996) conclude with a strong statement that a careful study of the role of simulation models in water resource negotiations requires analysis of a number of strategic, tactical and managerial aspects of model use. Since models are, in essence, important generators of inferred information, these factors are also important in evaluating information systems for integrated water resource management.

In most decision-making situations, the models are a means to help organise a learning or bargaining exercise, where it is important that it provides a framework, a mirror for our thinking, arguments, or justification for compromise. To achieve success, the water resource management teams, consisting inter alia of top level scientific consultants to stakeholders in the CMAs, will have to embrace double-loop learning. Such learning re-examines fundamental assumptions (Liedtka et al., 1997) underlying information generation.

\section{Myth: More information leads to better decisions}

More information is not necessarily better. Senge et al. (1995) highlight the crucial importance of recognising that information is first interpreted through the "lenses of the human mind" before its value and relevance to the debate is understood and verbalised. Senge et al. (1995) explored the notion "that all that managers need for better decision-making is more information ..." They point out that this notion misses the critical aspect of information interpretation. In support of their argument, they quote the findings of Sterman (1989) in a study on misperception of feedback in dynamic decision-making. Sterman says that research results directly contradict the assumption that all that managers need for better decision-making is more information. He reported that many studies have found that even knowledgeable and experienced decision-makers often filter their information through non-systemic mental models, construing symptoms as causes and reacting in ways that make problems worse rather than better. Senge et al (1995) concede that increased access to information may be a step in the direction of enhancing learning but that ultimately it is the interpretation of the information which is the key.

\section{Installed modelling systems}

Installed modelling systems will enable CMAs to address the contradictory calls for affordable modelling at the same time as greatly increased complexity, scalability, accessibility and integration. Such systems are set up and then kept operational for use in ongoing learning, research, strategising and consensusbuilding amongst role players. They are a fast-growing reality and they also provide opportunity for those who have invested in them to reap the benefits of speed to "setup" scenarios and designs on subsets of the large system. They, therefore, provide the framework of what can become a steady source of revenue. Such systems need maintenance, they spawn research needs and are also operationally successful because they address the timeliness issues which is so important in today's fast-moving world in which contentious water resource issues are becoming much more commonplace

\section{Finding time for the complexities of installed systems}

A frequent question is how can one afford the time to learn and install such comprehensive systems. The answer to this question has several parts: 
- $\quad$ one does not have to do it all oneself, work in teams;

- because it is comprehensive, others will contribute to it and save you the time on those sections on which they are skilled;

- $\quad$ ask oneself where one currently spends one's time on such projects

- $\quad$ finding land use data; soils data; climatic data; streamflow data

- $\quad$ patching gaps in climatic data

- checking, checking, checking all aspects of each piece of data,

- endless reformatting to get all these data into the unique form required for your model

- finding data covering abstractions from the stream,

- finding a history of past decisions with respect to allocation,

- gaining the trust of the interested and affected parties

By developing and using installed systems, these jobs will be done once and then be accessible to all. Checking input data is a function which will be performed by every responsible user. However, since such users are freed from the time-consuming duty of finding and reformatting such data, the intensity and forms of checking will be different and the error rate should drop sharply with time as more people scrutinise and clean up the data for future common use. Countless industries improve quality in the same way, generically speaking. The large savings in time which are made in the data setup and checking can then be used to manage the extra complexity. Practice also makes complexity manageable as the users of ARC/ INFO (2 400 commands) will testify.

An analysis of the function of each subroutine in most modelling systems will reveal that approximately $70 \%$ of such routines are dealing with input/output, pre-processing, post-processing, GIS, hypertext, time series management or some other form of "service utility" which is not germane to the hydrological process being modelled. It is in this $70 \%$ that huge productivity gains can be made through common inter-operability standards.

The pressure to standardise on these to save time will come from top level scientific consultants who are employed by stakeholders. These experts who will have the trust of national stakeholder groupings e.g. forestry, sugar and mining to advise them in several CMA areas will be required to move rapidly to the core of the negotiation issue. They will not want to spend days fighting issues relating to non-conformity to inter-operability standards before they are even able to start addressing the real issues with their negotiating opponents.

\section{Key functional requirements for installed modelling systems}

In essence, water resource modelling systems perform processes on sequences of time-dependent data. In addition, such systems must be flexible in terms of the temporal and spatial resolution of the processes being modelled. Arguably, the most important key functional element of an installed modelling systems is ,therefore, a top class time-series management system.

Secondly, the modelling system and the service utility shell which serves as an interface between most of the beneficiaries of the system should be able to operate in an optimised client server environment in which both shared and local information and processing are possible. Thirdly, the system should be able to model both quantity and quality both on the land and in the stream. It should be able to model both point and non-point sources of conservative and non-conservative pollutants. Fourthly, it should be able to inter-operate with the functional modules of other systems, where sensible, in terms of the science involved. The networks of flows, abstractions, return flows, pumping and release regimes within a catchment are most often complex. Keeping track of all these in a functional, flexible and robust manner is an essential requirement of an installed modelling system framework. Furthermore, the flows in each reach or branch of the network will be "allocated to somebody" and it is important that the backbone system keeps track of the categories or "labels" on this water. Fifthly, installed systems should be capable of tracking their own internal variable as they execute and be able to produce conditional responses. This is essential for modelling the responses to conditional interventions by humankind. Programming of such "rules" should ideally be made in the users' control input (UCI), since to do this in the source code is clumsy and inflexible and leads to impractical version control difficulties.

The service utility shell which serves it should ideally have a graphical user interface (GUI), make use of geographical information systems (GIS), have links to hypertext help files, pictorial data bases and be able to produce appropriate reports. It should act as a client platform to shared software on a central server which is accessible by all major stakeholders.

Is all this wishful thinking or do such systems exist and are they being used in everyday practice to manage water resources in an inter-disciplinary, inter-organisational context? Such systems do exist and are being used and supported by large organisations. What is more, the models and the many service utilities which interface to them are being distributed free. In the public domain, the most well-known of these is the HSPF system. It is not practical in a paper of this length to describe a number of models which have some of the attributes of HSPF. The HSPF was selected for special mention since it is so comprehensive and so widely used in the USA and elsewhere for installed systems modelling.

The HSPF software outlined briefly in this paper, has all the above capability and is linked to two such utilities developed under contract to the EPA and available in the public domain. These are the generalised scenario generator software (GenScn) (EPA, 1997) and better assessment science integrating point and non-point sources (BASINSV2.0) (Lahlou et al., 1998) software which link ArcView 3.1 and Arc Explorer software to the model user control input, the watershed data management system(WDM) for managing time-series data and has the other functionality outlined above.

\section{The HSPF modelling system}

The hydrological simulation program Fortran (HSPF) is a key component of a number of successfully installed modelling systems in the world today. It was specifically designed for such a purpose (Russo, 1996). The rationale behind the development of HSPF is described below.

To get the benefits of simulation, a user must select a model from a bewildering array and then spend much effort amassing and manipulating the huge quantities of data which the model requires. If the modeller wishes to couple two or more sub-process models to simulate a complete process, he often encounters further difficulties. The underlying assumptions and/or structure of the sub-process models may make them somewhat incompatible. More frequently, the data structures are so different that coupling requires extensive data conversion work. One reason for these problems is that the boom in modelling work has not included enough work on the development of good model structures (Bicknell et al., 1996). That is, very few software packages for water resource modelling are built on a systematic framework in which a variety of process modules can fit. Recognising this, the US Environmental 
protection Agency (EPA) commissioned the development of HSPF and have supported its growth. HSPF Version 11 was published in 1996 and Version 12 is imminent. The developers of HSPF overcame these problems as far as possible. HSPF consists of a set of modules arranged in a hierarchical structure, which permits the continuous simulation of a comprehensive range of hydrological and water quality processes (Russo, 1996).

The above techniques were chosen following the HSPF developers' experience, with sophisticated models, which indicated that much of the human effort is associated with data management. This fact, often overlooked by model builders, means that a successful comprehensive model must include a sound data management component. Otherwise, the user may become so entangled in data manipulation that his progress on the simulation work itself is drastically retarded. Consequently, the HSPF software is planned around a time-series management system operating on direct access principles. The simulation modules draw input from time series storage files and are capable of writing output to them. Because these transfers require very few instructions from the user, the problems referred to above are minimised.

The HSPF system was designed so that the various simulation and utility modules can be invoked conveniently, either individually or in tandem. HSPF follows a top-down approach emphasising structured design. The overall framework and the time-series management system were designed first. Then, work progressed down the structure from the highest, most general level to the lowest, most detailed one. Every level was planned before the code was written. Uniform data structures, logic figures, and programming conventions were used throughout, (Bicknell et al. 1996). Modules were separated according to function so that, as far as possible, they contained only those activities which are unique to them. Many concepts of object-oriented programming are present in HSPF. Structured design has made the system relatively easy to extend, so that users can add their own modules with relatively little disruption of the existing code. An example of this was the water budget of the ACRU modelling system (Schulze, 1995) which was added in just 55 working days by one computer scientist (Thorpe, 1999). This included studying the ACRU source code for the first time, extensive testing and preparing a most comprehensive hypertext write-up of the exact coupling procedure and source code changes.

\section{Creation of secondary efficiencies and opportunities}

Another legitimate and key concern with respect to installed modelling systems is that they may "shut out" innovative and vital modelling efforts aimed at specific aspects of the overall challenge. These efforts may be excellent but may lack the comprehensive coverage of functionality or the organisational muscle to themselves become "installed systems".

It is important to recognise that appropriate installed systems do not exclude specific contributions of finer spatial or temporal resolution or functional complexity. They enable time series generated by whatever means to be accommodated as input to more specialised models which may be required for a particular aspect of the integrated system. Installed modelling systems which are intended to be used as backbone systems but whose software design excludes the contribution of other models, should be rejected as they are anathema to the inclusive process of integration.

Paradoxically, installed systems which are open, restore the power to contribute, back to individuals. If one considers the overheads (listed above) required to set up models for catchments, then it is evident that this is what is currently excluding individuals and small groups from playing a meaningful role at the levels of complexity and functionality required by integrated water resource management. In the name of "freedom" and autonomy, we are duplicating much baggage which is imprisoning us through an overload of mundane work. It is also putting an inordinate emphasis on "who has got the data", rather than who has the skill, creativity and systems understanding.

\section{New bargaining paradigms need installed models}

Water allocation bargaining paradigms have and will continue to move from a rights basis to an interests basis. This trend is particularly prevalent where the issues contain high levels of uncertainty or where values and perceptions are at the core of disputes. Water issues are laden with uncertainty as well as values and perception differences and, therefore, it is predicted that groups will move towards interest-based negotiating strategies in the social process of water allocation. In the interest based-bargaining process, the role of the state is likely to be that of coach and referee, facilitating and ensuring a fair process. South Africa simply does not have the skilled resources or finances to do it any other way and, most importantly, nor do our neighbours. We have also all had plenty of opportunity to think about the appalling cost of conflict in this region. Some conflict over these issues is healthy and necessary and some is not. It will require wisdom and courage to discern which is which and to change where necessary.

It is well-known that the paradigms of bargaining influence the stakeholders' approaches to sharing of information and joint ventures. In the interest-based paradigm, the more powerful stakeholders, paradoxically, find it in their own interest to assist the weaker ones to understand the complexities of the issues at hand. Often this takes place through trusted intermediaries acting for the weaker stakeholders. This greater willingness to share and join efforts will free up time and skills to engage the higher levels of complexity which are so necessary. In addition, the state can then direct more of its resources at servicing the urgent need for delivery to previously disadvantaged communities.

The significance of this paradigm shift for modelling is profound. Firstly, it signifies an appropriate response to the strong external forces in the business environment of water resource management. Secondly, emphasis shifts, from the current pre-occupation with the "answer", to a greater appreciation for the role of the "process" whereby that "answer" was attained. At present, a frequent problem with conflict over water resources and the disintegrated way that catchments are managed is that one person's "answer" is often the root cause of another's problem.

\section{Modelling dynamic human intervention}

Being able to program the IF , THEN, ELSE type conditional statements which are necessary to model feedback consequences of human interventions in the natural water resources systems in catchments is not new. Such programming is generally performed in the source code of the simulation model and, hence, when changes are made to these operating rules, the source code has to be modified, recompiled and a "new version" of the model is created. This is a severe limitation, since to keep up with the variety of interventions that CMAs will be required to consider, results in severe version and quality control problems in the source code of the modelling systems. The HSPF modelling system (Bicknell et al 1996) has overcome this limitation by enabling such conditional special actions, as they are termed in the HSPF system, to be 
programmed in the user control input (UCI), thus eliminating hugely problematic version and quality control issues. This is a feature of HSPF which is used widely in the USA and which will, undoubtedly, be exceptionally useful for CMAs in South Africa.

\section{Synthesis, dialogue, practice and data-led modelling}

The discussions in this paper have shown that the systems which encapsulate the hydrological cycle and integrated water resource management are detailed, complex and dynamic. As Senge (1990) explains, there are two major types of complexity, both of which are present in water resource simulation modelling. These are the "detail complexity" of many variables and the "dynamic complexity" when "cause and effect" are not close in time and space and obvious interventions do not produce expected outcomes. Therefore, any person or group who aspires to play a meaningful role in such a system through the development and use of an integrated simulation modelling system must engage both types of complexity.

How do individuals or groups set about the task of jointly developing their thinking regarding such complex systems and, hence, understanding and go on to build complex system models? The answer to this question has a great many dimensions, some of which have been discussed in this paper. Sterman (1995) believes that the only system maps we can interpret mentally, will be trivial and incomplete compared to the complexity of the systems which we seek to understand. We can create more complex and realistic maps of our systems, but our intuition is then insufficient to provide the guidance into their dynamics. One approach to addressing the above dilemma is to use computer simulation and extensive practice. The ability and intellect required to develop and manage these tools requires extensive practice as many of them require an interplay between the subconscious and the conscious. They also require extensive dialogue and the development and projection of new language to describe the new concepts.

Implicit in the discussion which follows, is the belief that the regular use of installed modelling systems will enable individuals and groups to gain the practice required to mobilise subconscious processes. Computer-based models accurately and speedily calculate the consequences of the assumptions in our system maps, no matter how complex. This ability is a most important aspect of one's systems thinking training, as Sterman (1995) emphasises. He points out that without modelling we may think we are learning to think holistically when we are actually learning to jump to conclusions. The implications of our assumptions can be shown by a well-crafted and tested computer model which enables us to close the feedback loop by which we learn. To do this, we generally need to synthesise a great deal of information about the subject into a few key concepts and procedures. Synthesis is now surfacing and will take its place beside analysis as an important approach to the challenges of life. This is the view of Hall (1996) who goes on to add that group and multidisciplinary efforts predominate in synthesis activities. Synthesis, he reflects, provides a framework for guiding analysis, research, development, management and education and simulation models provide a framework for such a synthesis of ideas.

Senge (1990) offers some further important generic traits of simulation modelling. These are part of the reason why they are so valuable in the pursuit of integrated water resource management. Models give the impression of speeding up or slowing down time, compressing space and isolating variables. They offer an experimental orientation in which we can contemplate the consequences of our intended decisions and the fear of failure is almost eliminated. They offer the opportunity to pause for reflection, to develop theory-based strategy and cultivate institutional memory. Models are ideal catalysts, and indeed vehicles, as Goodman (1995) explains, to engage teams in deeper sets of systems learning and allow them to experiment with the consequences of their thinking.

There is often a strong pre-occupation with data to prove that the scenarios are correct. Senge (1990) makes a valuable contribution to this discussion through his comments on the use of modelling at Shell. Senge (1990) reflects that it did not matter whether managers at Shell believed the planners' scenarios absolutely. It mattered only that they became engaged in figuring out the implications. This example is so relevant to water resource systems simulation modelling since its key benefit is to enable developers and users to explore their mental models, the consequences of change and to engage in deeper conversations. In this way they also address a fundamental but often overlooked prerequisite to getting the right answer, and that is to ask the right question.

The testing of whether the structure replicates the performance that we observe in the real world is crucial. However, modellers and managers often place undue emphasis on this aspect of modelling. It must be remembered that often the observed data sets are extremely limited and, therefore, all we can say with respect to such tests is that the model performs reasonably within the range of the observed data. The reason that we model, however, is to enable extrapolation in time, space and quantity beyond the original base of observed information.

\section{Conclusions}

Bohm(1987), a world-renowned nuclear physicist, connects mental models and the systems perspective explicitly when he argues that the purpose of science is not the accumulation of knowledge. Since, states Bohm, "all scientific theories are eventually proved false". Bohm (1987) believes that the real purpose of science is to create "mental maps" that guide and shape our perceptions and actions, bringing about a constant and mutual participation between nature and consciousness. Bohm sees thought as largely a collective phenomenon and dialogue as a process to develop a "pool of common meaning" which cannot be accessed individually. Put another way, Bohm believes that the whole organizes the parts.

How do we change our culture and behaviour to become congruent with these higher levels of conception?

The move from compartmentalisation to integration is a major change affecting many aspects of organizational behaviour and especially the phenomenon of change. Understanding the power of mental models ("maps") is central to understanding change.

The installed modelling systems of which this paper speaks will be a significant contribution towards making the implicit mental models of the stakeholders explicit and, hence, contribute to management, change and resolution of conflict in the social process of water allocation.

\section{Acknowledgements}

I would like to thank the Water Research Commission, my colleagues in the water research and management fields in Southern Africa and especially those in the Computing Centre for Water Research (CCWR) and the Kruger National Park Rivers Research Programme (KNPRRP) for providing the many opportunities for the insight and learning which are reflected in this paper. 


\section{References}

BOHM D (1987) Science, Order and Creativity. Bantam Books, New York.

BICKNELL BR, IMHOFF JC, KITTLE JL, DONIGIAN AS and JOHANSON RC (1996) Hydrological Simulation Program FORTRAN. User's Manual for Release 11. US EPA. Environmental Research Laboratory, Athens, GA, in co-operation with U.S. Geological Survey, Office of Surface Water, Reston, VA.

CHESBROUGH HW and TEECE DJ (1996) Organising for innovation. Integrated virtual alliances. When is virtual virtuous? Harvard Bus. Rev. Jan-Feb 1996

COVEY SR (1994) The Seven Habits of Highly Effective People: Powerful Lessons in Personal Change. Simon and Schuster, London.

CUSUMANO MA (1997) How Microsoft makes large teams work like small teams. Sloan Manage. Rev. Fall

DWAF (1997) White Paper on a National Water Policy for South Africa. Department of Water affairs and Forestry, Pretoria.

EPA (1997) Generalised Scenario Generator Software (GenScn). United States Environmental Protection Agency. Office of Water

GOODMAN M (1995) Moving into computer modelling. In: Senge P, Roberts C, Ross RB, Smith BJ and Kleiner A (eds.) The Fifth Discipline Fieldbook: Strategies and Tools for Building a Learning Organisation. Nicholas Brealey, London.

HALL CW (1996) The age of synthesis. Resour. March. 12-14.

LAHLOU M, SHOEMAKER L, CHOUDHURY S, ELMER R, HU A, MANGUERRA H and PARKER A (1998) Better Assessment Science Integrating Point and Non-point Sources. BASINS Versions 2.0 United States Environmental Protection Agency. Office of Water. (www.epa.gov.ost/basins/)

LIEDTKA JM, HASKINS ME, ROSENBLUM JW and WEBER J (1997) The generative cycle: Linking knowledge and relationships. Sloan Manage. Rev. Fall.

QUADIR G, DUECK M, ABBOTT F, EL-BAZ K, TAKEUCHI H and PHIENN (1999) Report of the thematic panel on information and communication technology and its implications for water resources.
World Water Vision. International Water and Sanitation Centre, The Hague and the Swedish International Development Agency

REITSMA R, ZIGURS I, LEWIS C, WILSON V and SLOANE A (1996) Experimentation with simulation models in water-resources negotiations. Water Resour. Plann. and Manage. Jan-Feb. 64-70.

RUSSO R (1996) Cited in Bicknell et al. (eds.) Hydrological Simulation Program - FORTRAN. User's Manual for Release 11. U.S. E.P.A. Environmental Research Laboratory, Athens, GA, in co-operation with U.S. Geological Survey, Office of Surface Water, Reston, VA.

SCHULZERE(1995) Hydrology andAgrohydrology-A Text to Accompany the ACRU 3.00 Agrohydrological Modelling System. Dept. Agric. Eng., Univ. of Natal, Pietermaritzburg, South Africa.

SENGE P, ROBERTSC, ROSS RB, SMITH BJ and KLEINER A (1995) The Fifth Discipline Fieldbook-Strategies and Tools for Building a Learning Organisation. Nicholas Brealey, London.

SENGE P (1990) The leader's new work : Building learning organisations. Sloan Manage. Rev. 32 (1)

STERMAN J (1989) Misperception of feedback in dynamic decisionmaking. Organ. Behav. and Hum. Dec. Processes. 43 (3) 301.

STERMAN J (1995) cited in Senge P, Roberts C, Ross RB, Smith BJ and Kleiner A (eds.) The Fifth Discipline Fieldbook-Strategies and Tools for Building a Learning Organisation. Nicholas Brealey, London.

TAYLOR W C (1994) Control in the age of chaos. Harvard Bus. Rev. NovDec.

THORPE J (1999) Personal communication. Computing Centre for Water Research, University of Natal.

TURTON AR (1999) Water Scarcity and Social Adaptive Capacity: Towards an Understanding of the Social Dynamics of Managing Water Scarcity in Developing Countries . MEWREW Occasional Paper 9 , Water Issues Study Group, Department of Geography, SOAS Univesity of London

UPTON DM and MCAFEE (1996) The real virtual factory. Harvard Bus. Rev. Jul-Aug. 123-133.

ZACHARY GP (1994) Show-Stopper. The Breakneck Race to Create Windows NT and the Next Generation at Microsoft. The Free Press, New York (reviewed by Taylor (1994). 